\title{
Temperature Dependence of the ${ }^{127}$ I Quadrupole Coupling in Periodates with Alkyl- or Aryl-Substituted Cations of Main Group V*
}

\author{
Dagmar G. Klobasa, Paul K. Burkert, and Gerhard Müller \\ Anorganisch-chemisches Institut der Technischen Universität München
}

Z. Naturforsch. 41 a, 330-334 (1986); received July 22, 1985

\begin{abstract}
${ }^{127}$ I solid state NMR studies of metaperiodates with alkyl- or aryl-substituted cations of main group $\mathrm{V}$ revealed second order quadrupole effects with quadrupole coupling constants in the range of $2-7 \mathrm{MHz}$.

In $\left(\mathrm{C}_{2} \mathrm{H}_{5}\right)_{4} \mathrm{PIO}_{4}$ and $\left(\mathrm{C}_{2} \mathrm{H}_{5}\right)_{4} \mathrm{AsIO}_{4}$ the ${ }^{127} \mathrm{I}$ quadrupole coupling constants show normal temperature coefficients $\bar{\alpha}$ in the order of $-10^{-4} \mathrm{~K}^{-1}$ for $186 \mathrm{~K}<T<300 \mathrm{~K}$.

For the metaperiodates with aryl-substituted cations $\left(\mathrm{C}_{6} \mathrm{H}_{5}\right)_{4} \mathrm{P}^{+}, \quad\left(\mathrm{C}_{6} \mathrm{H}_{5}\right)_{4} \mathrm{As}^{+}$and $\left(\mathrm{C}_{6} \mathrm{H}_{5}\right)_{4} \mathrm{Sb}^{+}$complicated temperature dependences of the ${ }^{127} \mathrm{I}$ quadrupole interaction with phase transitions and anomalous positive temperature coefficients $+0.2 \cdot 10^{-2} \mathrm{~K}^{-1} \leqq \bar{\alpha} \leqq+0.8 \cdot 10^{-2} \mathrm{~K}^{-1}$ were observed.

The relevance of possible mechanisms for the anomalous temperature coefficients, like breakdown of $d_{\pi}-p_{\pi}$ backbonding, negative pressure coefficients, charge transfer, orientational change of the EFG-tensor axes system and influence of reorientational motions is discussed for these compounds, including results from an X-ray investigation of $\left(\mathrm{C}_{6} \mathrm{H}_{5}\right)_{4} \mathrm{AsIO}_{4}$ and ${ }^{1} \mathrm{H}$-solid state NMR measurements.
\end{abstract}

\section{Introduction}

On measuring second order quadrupole effects in ${ }^{127}$ I solid state NMR of metaperiodates with aryl- or alkyl-substituted cations of main group $\mathrm{V}$ we observed different behaviour of the temperature coefficients $\bar{\alpha}$ of the ${ }^{127} \mathrm{I}$ quadrupole interactions. For the metaperiodates with aryl-substituted cations [1] like tetraphenylphosphonium- (1), tetraphenylarsonium- (2) and tetraphenylstibonium-metaperiodate (3) anomalous positive temperature coefficients $\bar{\alpha}$ were found. The compounds (1) and (2) show this anomalous behaviour after a phase transition detected by the typical change of the quadrupole coupling constants in the ${ }^{127} \mathrm{I}$ NMR powder spectra. (3) has not phase transition in the whole temperature range measured [1].

In the metaperiodates with alkyl-substituted cations $\left(\mathrm{C}_{2} \mathrm{H}_{5}\right)_{4} \mathrm{P}^{+}(\mathbf{4})$ and $\left(\mathrm{C}_{2} \mathrm{H}_{5}\right)_{4} \mathrm{As}^{+}(\mathbf{5})$ the ${ }^{127} \mathrm{I}$

* Presented at the VIIIth International Symposium on Nuclear Quadrupole Resonance Spectroscopy, Darmstadt, July $22-26,1985$.

Reprint requests to Priv.-Doz. Dr. P. K. Burkert, Anorganisch-chemisches Institut, Technische Universität München, Lichtenbergstr. 4, D-8046 Garching. quadrupole coupling constants show normal temperature coefficients [2] in the order of $\bar{\alpha}=$ $-10^{-4} \mathrm{~K}^{-1}$ for $186 \mathrm{~K}<T<300 \mathrm{~K}$. In tetraethylarsonium metaperiodate $(\mathbf{5})$ a phase transition for $T=186 \mathrm{~K}$ additionally occurs, where the asymmetry parameter $\eta$ does not vanish.

A comprehensive general discussion of the anomalous temperature coefficients $\bar{\alpha}$ is difficult [3], because special intra- and intermolecular interactions appear to be the origin of these effects. The most important possibilities considered until now are: the breakdown of $\mathrm{d}_{\pi}-\mathrm{p}_{\pi}$ backbonding $[4,5]$; the occurrence [6] of sufficiently large negative pressure coefficients $(\partial v / \partial p)_{T}$ in the KushidaBenedek-Bloembergen theory; charge transfer from $\pi$ - to $\sigma$-orbitals of adjacent atoms [7, 8]; continuous orientational change of the principal axes system of the electric field gradient (EFG) tensors $\tilde{q}_{i k}[9-13]$ and the influence of reorientational motions [14-19].

With the main mechanisms listed above and additional results from an X-ray investigation of $\left(\mathrm{C}_{6} \mathrm{H}_{5}\right)_{4} \mathrm{AsIO}_{4}$ and ${ }^{1} \mathrm{H}$ solid state NMR measurements the anomalous ${ }^{127}$ I temperature coefficients $\bar{\alpha}$ will be discussed. 


\section{Experimental}

\subsection{Instrumentation}

The quadrupole coupling constants $e^{2} q Q / h$ of the compounds $\mathrm{Ph}_{4} \mathrm{E}^{+} \mathrm{IO}_{4}^{-}(\mathrm{E}=\mathrm{P}, \mathrm{As}, \mathrm{Sb} ; \mathrm{Ph}=$ $\left.\mathrm{C}_{6} \mathrm{H}_{5}\right)$ and $\mathrm{Et}_{4} \mathrm{E}^{+} \mathrm{IO}_{4}^{-} \quad\left(\mathrm{E}=\mathrm{P}, \quad \mathrm{As} ; \mathrm{Et}=\mathrm{C}_{2} \mathrm{H}_{5}\right)$ (1)-(5) were determined from second order quadrupole splittings of the ${ }^{127}$ I solid state NMR spectra. For these measurements the FT-NMR spectrometer Bruker CXP 200 equipped with a superconducting magnet $\left(B_{0}=4.698 \mathrm{~T}\right)$ was used. The resulting ${ }^{127} \mathrm{I}$ Larmor frequency $v_{\mathrm{L}}$ was 40.19 MHz. Temperature dependent experiments were carried out using the thermostat Bruker B-VT 1000 with a temperature tolerance $\Delta T= \pm 1 \mathrm{~K}$. Experimental errors of the reported quadrupole coupling constants are in the range of $\Delta\left(e^{2} q Q / h\right)=$ $\pm 0.03 \mathrm{MHz}$ mainly caused by dipolar broadening of the quadrupole split ${ }^{127}$ I NMR powder patterns.

\subsection{Preparation of the Compounds $(\mathbf{1})-(\mathbf{5})$}

The preparation and the analytical data of $\mathrm{Ph}_{4} \mathrm{E}^{+} \mathrm{IO}_{4}\left(\mathrm{E}=\mathrm{P}, \mathrm{As}, \mathrm{Sb} ; \mathrm{Ph}=\mathrm{C}_{6} \mathrm{H}_{5}\right)$ are described in our publication 1.c. [1]. The starting compounds for the preparation of (4) and (5) $\mathrm{Et}_{4} \mathrm{PBr}$ and $\mathrm{Et}_{4} \mathrm{AsI}$ were synthesized by literature methods $[20-24]$. The quarternary phosphonium- and arsonium halogenides are dissolved in water and then their hydroxides $\mathrm{Et}_{4} \mathrm{E}^{+} \mathrm{OH}^{-}(\mathrm{E}=\mathrm{P}$, As; $\mathrm{Et}=$ $\mathrm{C}_{2} \mathrm{H}_{5}$ ) are formed by application of a strong basic anion exchanger (Merck, Ionenaustauscher III). These basic solutions are neutralized by an equivalent amount of pure, solid periodic acid. After evaporation of the solvent and drying of the white polycrystalline compounds in high vacuum at room temperature the desired periodates $(\mathbf{4}, \mathbf{5})$ are accessible in yields of $75-85 \%$. Recrystallization from water gives analytical pure samples. Their analytical data are presented in the following. The melting points were not determined to prevent violent explosions.

$\mathrm{C}_{8} \mathrm{H}_{20} \mathrm{O}_{4} \mathrm{IP}(338.12)$

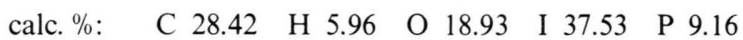
found \%: $\quad$ C 28.73 H 5.77 O 17.54 I $37.91 \quad$ P 9.00

$\mathrm{C}_{8} \mathrm{H}_{20} \mathrm{O}_{4} \mathrm{IAs}$ (382.07)

calc. \%: $\quad$ C 25.15 H 5.28 O 16.75 I 33.22 As 19.61 found \%: C 25.34 H 5.20 O 17.03 I 32.99 As 19.65

\section{Results}

(a) Figure 1 shows the typical second order ${ }^{127} \mathrm{I}$ quadrupole splittings $\Delta v$ of the central ${ }^{127} \mathrm{I}$ NMR transition $(+1 / 2 \leftrightarrow-1 / 2)$ dependent on temperature for $\left(\mathrm{C}_{2} \mathrm{H}_{5}\right)_{4} \mathrm{AsIO}_{4}$. For polycrystalline material the dependence of the quadrupole splitting $\Delta v$ upon the spin quantum number $I$ and the asymmetry

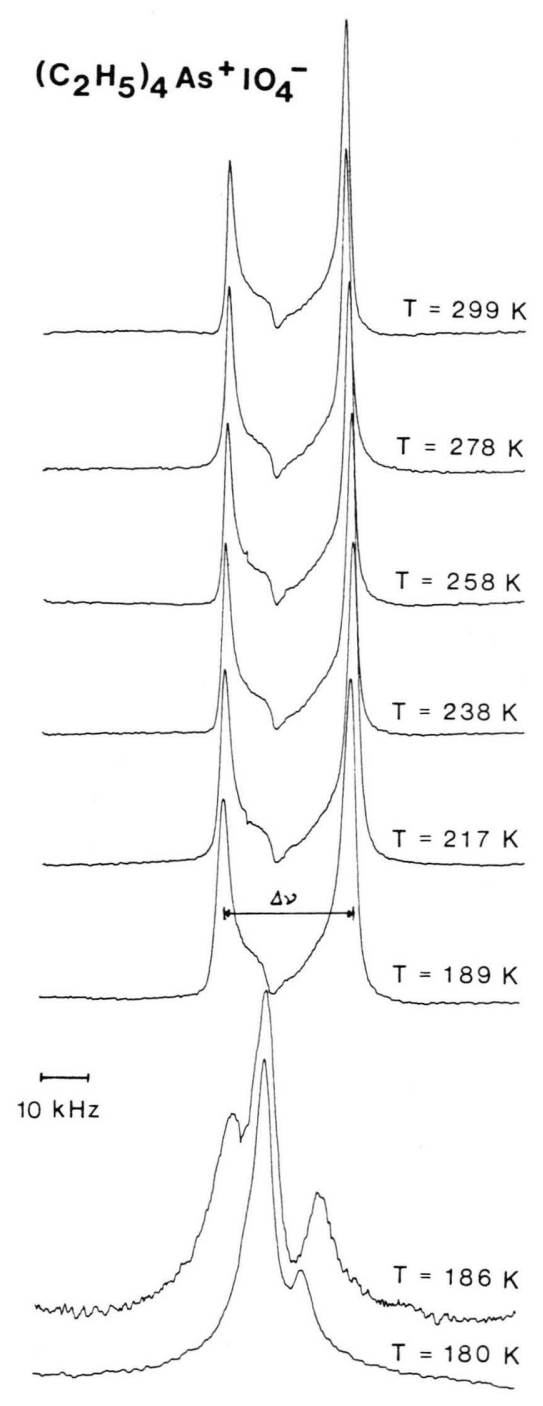

Fig. 1. Temperature dependence of the ${ }^{127}$ I NMR spectra of polycrystalline $\left(\mathrm{C}_{2} \mathrm{H}_{5}\right)_{4} \mathrm{AsIO}_{4}$ with second order quadrupole splitting $\Delta v$. - Larmor frequency: $v_{\mathrm{L}}=40.19$ $\mathrm{MHz}$; sweep range: $\mathrm{SW}=100 \mathrm{kHz}$; pulse program: one cycle pulses; pulse width: $6 \mu \mathrm{s}$; recycle time: $30 \mathrm{~ms}$. 
parameter $\eta[25,26]$ is given by

$$
\Delta v=\frac{v_{Q}^{2}}{144 v_{\mathrm{L}}}\left[I(I+1)-\frac{3}{4}\right] f(\eta)
$$

with

and

$$
v_{Q}=\frac{e^{2} q Q}{h} \frac{3}{2 I(2 I-1)}
$$

$$
f(\eta)=16(1-\eta)+(3-\eta)^{2} \text { for } \eta \leqq 0.33 \text {. }
$$

The comparison of these ${ }^{127}$ I NMR powder spectra with our earlier measurements of scheelite-structured metaperiodates $[17,19]$ gives evidence of the case $\eta \rightarrow 0$ for $\mathrm{Ph}_{4} \mathrm{E}^{+} \mathrm{IO}_{4}^{-}(\mathbf{1})-(3)$ in the region $\bar{\alpha}>0$ and for $\mathrm{Et}_{4} \mathrm{E}^{+} \mathrm{IO}_{4}^{-}(\mathbf{4}, \mathbf{5})$ where $\bar{\alpha}<0$. From Eq. (1) the quadrupole coupling constant results to be in this case:

$$
e^{2} q Q / h=4 \sqrt{2} \sqrt{(\Delta v) \cdot v_{\mathrm{L}}} .
$$

The values of $e^{2} q Q / h$ for the metaperiodates with alkyl-substituted cations $\left(\mathrm{C}_{2} \mathrm{H}_{5}\right)_{4} \mathrm{P}^{+}$(4) and

Table 1. Temperature dependence of second order ${ }^{127} \mathrm{I}$ NMR quadrupole splitting $\Delta v$ of $\left(\mathrm{C}_{2} \mathrm{H}_{5}\right)_{4} \mathrm{E}^{+} \mathrm{IO}_{4}^{-}(\mathrm{E}=\mathrm{P}$, As) and temperature coefficients $\bar{\alpha}$. Results for $\left(\mathrm{C}_{6} \mathrm{H}_{5}\right)_{4} \mathrm{E}^{+} \mathrm{IO}_{4}^{-}$ $(\mathrm{E}=\mathrm{P}, \mathrm{As}, \mathrm{Sb})$ : see our measurements in l.c. [1].

\begin{tabular}{llllll}
\hline$\left(\mathrm{C}_{2} \mathrm{H}_{5}\right)_{4} \mathrm{PIO}_{4}$ & \multicolumn{5}{c}{$\left(\mathrm{C}_{2} \mathrm{H}_{5}\right)_{4} \mathrm{AsIO}_{4}$} \\
\hline$T$ & $\Delta v$ & $e^{2} q Q / h$ & $T$ & $\Delta v$ & $e^{2} q Q / h$ \\
{$[\mathrm{~K}]$} & {$[\mathrm{kHz}]$} & {$[\mathrm{MHz}]$} & {$[\mathrm{K}]$} & {$[\mathrm{kHz}]$} & {$[\mathrm{MHz}]$} \\
\hline 302 & 26.76 & 5.87 & 299 & 23.93 & 5.55 \\
289 & 26.76 & 5.87 & 289 & 23.93 & 5.55 \\
278 & 26.95 & 5.89 & 278 & 24.02 & 5.56 \\
268 & 27.05 & 5.90 & 268 & 24.51 & 5.61 \\
258 & 27.25 & 5.92 & 258 & 25.29 & 5.70 \\
248 & 27.34 & 5.93 & 248 & 25.59 & 5.74 \\
238 & 27.44 & 5.94 & 238 & 26.07 & 5.79 \\
228 & 27.64 & 5.96 & 228 & 26.27 & 5.81 \\
217 & 28.03 & 6.00 & 217 & 26.47 & 5.83 \\
207 & 28.42 & 6.05 & 207 & 26.56 & 5.84 \\
197 & 28.61 & 6.07 & 197 & 26.37 & 5.82 \\
187 & 28.71 & 6.08 & & & \\
177 & 28.81 & 6.09 & & & \\
\hline Aver & & & & &
\end{tabular}

Average temperature coefficient

$$
\begin{aligned}
\bar{\alpha}= & \frac{2}{e^{2} q Q / h\left(T_{1}\right)+e^{2} q Q / h\left(T_{2}\right)} \\
& \cdot \frac{e^{2} q Q / h\left(T_{2}\right)-e^{2} q Q / h\left(T_{1}\right)}{T_{2}-T_{1}}
\end{aligned}
$$

\begin{tabular}{lll}
\hline Compound & Nucleus & $\bar{\alpha}\left[\mathrm{K}^{-1}\right]$ \\
\hline$\left(\mathrm{C}_{6} \mathrm{H}_{5}\right)_{4} \mathrm{PIO}_{4}$ & ${ }^{127} \mathrm{I}$ & $+0.2 \cdot 10^{-2}$ \\
$\left(\mathrm{C}_{6} \mathrm{H}_{5}\right)_{4} \mathrm{AsIO}_{4}$ & ${ }^{127} \mathrm{I}$ & $+0.2 \cdot 10^{-2}$ \\
$\left(\mathrm{C}_{6} \mathrm{H}_{5}\right)_{4} \mathrm{SbIO}_{4}$ & ${ }^{127} \mathrm{I}$ & $+0.8 \cdot 10^{-2}$ \\
$\left(\mathrm{C}_{2} \mathrm{H}_{5}\right)_{4} \mathrm{PIO}_{4}$ & ${ }^{127} \mathrm{I}$ & $-3.0 \cdot 10^{-4}$ \\
$\left(\mathrm{C}_{2} \mathrm{H}_{5}\right)_{4} \mathrm{AsIO}_{4}$ & ${ }^{127} \mathrm{I}$ & $-6.5 \cdot 10^{-4}$ \\
\hline
\end{tabular}
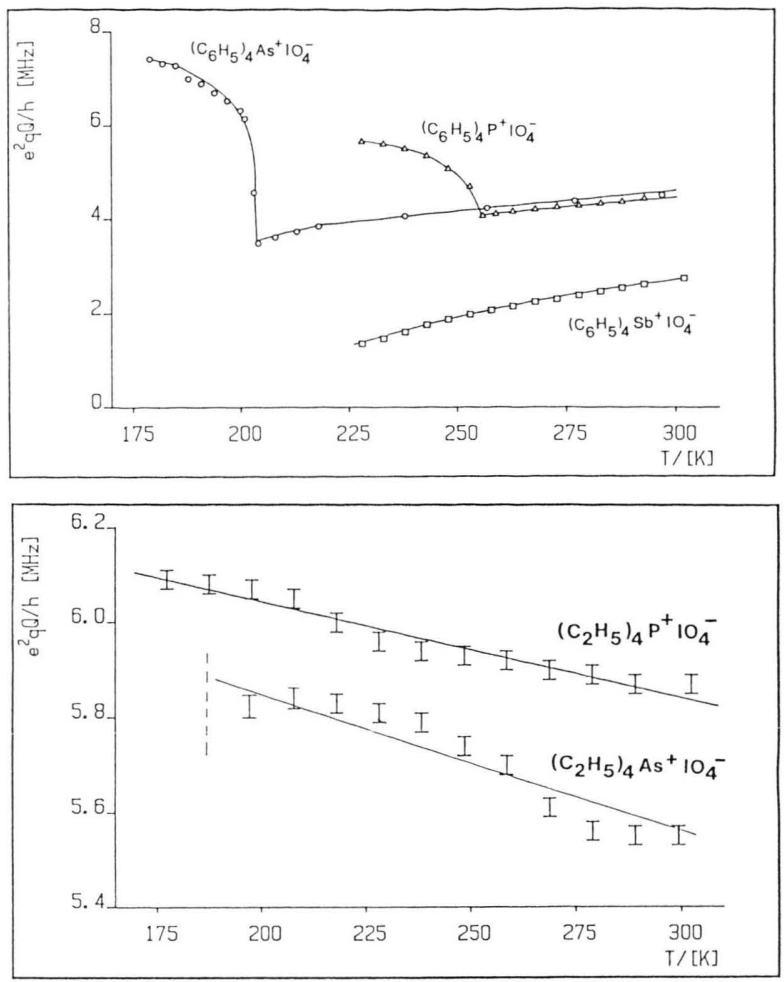

Fig. 2. Temperature dependence of ${ }^{127} \mathrm{I}$ quadrupole coupling constants $e^{2} q Q / h$ measured by second order quadrupole effects in ${ }^{127} \mathrm{I}$ powder spectra of $\left(\mathrm{C}_{6} \mathrm{H}_{5}\right)_{4} \mathrm{E}^{+} \mathrm{IO}_{4}^{-}$ $(\mathrm{E}=\mathrm{P}, \mathrm{As}, \mathrm{Sb})$ from our measurements 1.c. [1] compared with the results of $\left(\mathrm{C}_{2} \mathrm{H}_{5}\right)_{4} \mathrm{E}^{+} \mathrm{IO}_{4}^{-}(\mathrm{E}=\mathrm{P}$, As) with values of $e^{2} q Q / h$ from Table 1 .

$\left(\mathrm{C}_{2} \mathrm{H}_{5}\right)_{4} \mathrm{As}^{+}(\mathbf{5})$ listed in Table 1 are calculated from (2). Their temperature dependence is shown in Fig. 2 together with our earlier measurements [1] of the metaperiodates (1)-(3) with aryl-substituted cations.

(b) The X-ray structure determination of $\left(\mathrm{C}_{6} \mathrm{H}_{5}\right)_{4} \mathrm{AsIO}_{4}$ is characterized by the following data:

$\mathrm{C}_{24} \mathrm{H}_{20} \mathrm{AsIO}_{4}, f_{w}=574.25$, tetragonal, space group I $\overline{4} \quad$ No. 82) $, a=b=12.552(2) \AA, c=6.854(1) \AA$, $V=1079.87 \AA^{3}, d_{\text {calc. }}=1.766 \mathrm{~g} \mathrm{~cm}^{-3}, Z=2, F(000)$ $=564, \mu\left(\mathrm{Mo}_{\alpha}\right)=30.1 \mathrm{~cm}^{-1}, \quad T=-40^{\circ} \mathrm{C}$, Mo$\mathrm{K}_{\alpha}, \lambda=0.71069 \AA, \quad$ graphite monochromator, Syntex P 2 1238 measured, unique reflections of which 1154 "observed" with $I \geqq 2.0 \sigma(I)$. Lorentzpolarization and empirical absorption correction.

$R=0.026, R_{w}=0.029, w=1 / \sigma^{2}\left(F_{0}\right)$ for 68 refined parameters, $\Delta \varrho(\text { final })_{\max }=+0.86 /-0.84 \mathrm{e}^{-3}$ (SHELX 76). Further details of the Crystal Structure Determination are available from Fachinformationszentrum Energie Physik Mathematik, D-7514 
Eggenstein-Leopoldhafen. Any request should be accompanied by the Depository Number CSD 51551, the names of the authors and the full citation of the journal.

(c) Additional solid state ${ }^{1} \mathrm{H}$ NMR measurements of the compounds $(\mathbf{1})-(\mathbf{3})$ showed broad ${ }^{1} \mathrm{H}$ signals with no measurable temperature dependence of their second moments $\left\langle(\Delta B)^{2}\right\rangle$ in the region of the anomalous values $\bar{\alpha}>0$. From the ${ }^{1} \mathrm{H}$ NMR spectra we obtained second moments $\left\langle(\Delta B)^{2}\right\rangle$ of $10.9 \mathrm{G}^{2}$ for $\left(\mathrm{C}_{6} \mathrm{H}_{5}\right)_{4} \mathrm{PIO}_{4}, 11.3 \mathrm{G}^{2}$ for $\left(\mathrm{C}_{6} \mathrm{H}_{5}\right)_{4} \mathrm{AsIO}_{4}$ and $10.1 \mathrm{G}^{2}$ for $\left(\mathrm{C}_{6} \mathrm{H}_{5}\right)_{4} \mathrm{SbIO}_{4}$ with experimental errors of $\pm 0.5 \mathrm{G}^{2}$.

\section{Discussion}

\subsection{Phase Transitions}

Figures 1 and 2 show phase transitions of the compounds (1), (2) and (5). In the low temperature modification of (1) and (2) a part of the $\mathrm{IO}_{4}^{-}$-tetrahedra suffers a very small distortion by insertion in the lattice. The other $\mathrm{IO}_{4}^{-}$-tetrahedra have a comparatively large EFG (see Fig. 2) as discussed earlier [1]. No phase transitions are found for the compounds (3) and (4). Figure 1 reveals a phase transition at $T=186 \pm 1 \mathrm{~K}$ for $\mathrm{Et}_{4} \mathrm{AsIO}_{4}(\mathbf{5})$. The flat descent of the frequency edges suggests the occurrence of an asymmetry parameter $\eta \neq 0$ for $T<186 \mathrm{~K}$, but the ${ }^{127}$ I quadrupole splitting of (5) becomes of the order of the dipolar broadening and therefore cannot be resolved from the ${ }^{127}$ I NMR signals.

\subsection{Temperature Coefficients}

In the low temperature phases of $\mathrm{Ph}_{4} \mathrm{PIO}_{4}$ and $\mathrm{Ph}_{4} \mathrm{AsIO}_{4}$ respectively in $\mathrm{Et}_{4} \mathrm{PIO}_{4}$ and $\mathrm{Et}_{4} \mathrm{AsIO}_{4}$ a negative temperature coefficient $\bar{\alpha}<0$ of the ${ }^{127} \mathrm{I}$ quadrupole interaction is observed (see Fig. 2 and Table 1). Obviously this describes the domination of the normal isochoric Bayer-term [2] $(\partial v / \partial T)_{V}$ in the Kushida-Benedek-Bloembergen theory [3]. Normal temperature coefficients $\bar{\alpha}<0$ are characteristic for all ${ }^{127} \mathrm{I}$ quadrupole interactions in the metaperiodates except for $\mathrm{NH}_{4} \mathrm{IO}_{4}[16,27]$ and for the metaperiodates with aryl-substituted cations, described in this work. The anomalous temperature coefficients $\bar{\alpha}>0$ for these compounds (1) $-(\mathbf{3})$ and for ammonium metaperiodate are in the order of $+10^{-2} \mathrm{~K}^{-1}$. Only a small number of substances shows anomalous temperature effects [4-17] with maximum values in the order of $\bar{\alpha} \approx+10^{-4} \mathrm{~K}^{-1}$. The discussion of relevant mechanisms [4-19] for the anomalous coefficients $\bar{\alpha}>0$ leads to the following conclusions:

(a) In the case of (1)-(3) temperature dependent intra-ionic $\pi$-backbonding effects $[4,5]$ or analogous charge transfer effects $[7,8]$ cannot be responsible for $\bar{\alpha}>0$, because otherwise all measured metaperiodates [19] should show this phenomenon.

(b) In the obtained ${ }^{127}$ I NMR spectra (see Fig. 1) of (1)-(3) the form of the quadrupole splitted signals does not give any indication of a continuous change of the asymmetry parameter $\eta[9-13]$. Therefore there is no evidence for an orientational change of the EFG-tensor $\tilde{q}_{i k}$, which was found to be the reason for $\bar{\alpha}>0$ in $\operatorname{Re}_{2} \mathrm{CO}_{10}$ or $\left(\mathrm{CH}_{3}\right)_{3} \mathrm{GeOReO}_{3}[9-13]$.

(c) The X-ray investigation of $\left(\mathrm{C}_{6} \mathrm{H}_{5}\right)_{4} \mathrm{AsIO}_{4}$ and the ${ }^{1} \mathrm{H}$ solid state NMR of $(\mathbf{1})-(\mathbf{3})$ indicate that there are two mechanisms which could contribute to $\bar{\alpha}>0$ : a sufficiently large negative pressure coefficient $(\partial v / \partial p)_{T}$ of the quadrupole interaction [6] and reorientational motions $[14-18]$ of the metaperiodate anion.

The X-ray structure determination of (2) shows discrete $\left(\mathrm{C}_{6} \mathrm{H}_{5}\right)_{4} \mathrm{As}^{+}$and $\mathrm{IO}_{4}^{-}$ions with crystallographically imposed $4\left(\mathrm{~S}_{4}\right)$ symmetry. In the crystal they are arranged in columns of stacked cations and anions running parallel to the crystallographic c-axis (see Figure 3). This is often observed in the packing of two tetrahedral ions [28].

The immediate substituent geometry of the arsonium centers (see Fig. 4) shows little deviation from ideal tetrahedral symmetry as manifested by $\mathrm{C}-\mathrm{As}-\mathrm{C}$ angles of $108.2(2)^{\circ}$ and 110.1(1) ${ }^{\circ}$. From Fig. 4 it is evident that the tilted arrangement of the fixed phenyl rings results in the overall $\overline{4}\left(\mathrm{~S}_{4}\right)$ symmetry required by the crystallographic site symmetry.

The cations are very voluminous and therefore they can have a pressure dependent influence [6] on $\bar{\alpha}>0$ described by the Kushida-Benedek-Bloembergen theory with sufficiently large negative pressure coefficient $(\partial v / \partial p)_{T}<0$.

From the $\mathrm{O}-\mathrm{I}-\mathrm{O}$ angles $\left(108(1)^{\circ}, 110.0(5)^{\circ}\right)$ a similar, nearly perfect tetrahedral symmetry may also be inferred for the periodate anions. However, the observed large anisotropic displacements of the oxygen atoms point to large thermal movement and/or partial disorder of these atoms. Thus a larger 


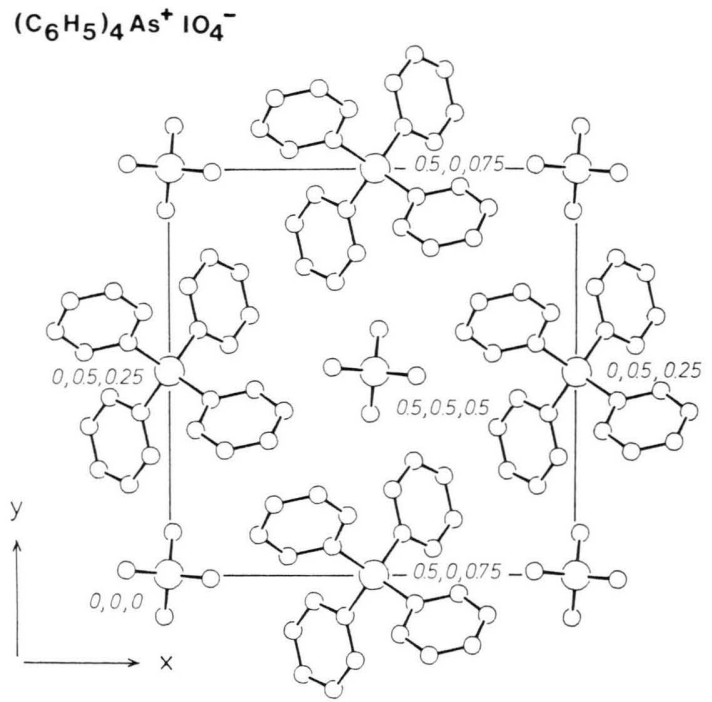

Fig. 3. Projection of the unit cell contents of $\left(\mathrm{C}_{6} \mathrm{H}_{5}\right)_{4} \mathrm{AsIO}_{4}$.

deviation from tetrahedral symmetry than indicated by the bond angles cannot be excluded on the basis of the X-ray data. The large ${ }^{1} \mathrm{H}$ second moments $\left\langle(\Delta B)^{2}\right\rangle$ of $(\mathbf{1})-(\mathbf{3})$ and their independence of temperature (see results $3(\mathrm{c})$ ) show that in $(\mathbf{1})-(\mathbf{3})$ $\bar{\alpha}>0$ cannot be correlated to dynamical effects of the cation in contrast to the reorientation model for $\mathrm{NH}_{4} \mathrm{IO}_{4}$ [18]. In (1) - (3) the dynamical contribution to the anomalous temperature coefficient $\bar{\alpha}$ of the ${ }^{127}$ I quadrupole interaction is caused by thermal

[1] P. K. Burkert and D. G. Klobasa, Z. Naturforsch. 40a, 274 (1985).

[2] H. Bayer, Z. Physik 130, 227 (1951).

[3] T. Kushida, G. B. Benedek, and N. Bloembergen, Phys. Rev. 104, 1364 (1956).

[4] R. Ikeda, D. Nakamura, and M. Kubo, J. Phys. Chem. 69, 2101 (1965).

[5] T. E. Haas and E. P. Marram, J. Chem. Phys. 43, 3985 (1965).

[6] R. G. Barnes and R. D. Enghardt, J. Chem. Phys. 29, 248 (1958).

[7] T. Kiichi, N. Nakamura, and H. Chihara, IV. Int. Symp. on NQR Spectroscopy, Osaka 1977.

[8] H. Chihara and N. Nakamura, Adv. in NQR (J. A. S. Smith, ed.), Vol. 4, 51, Heyden, London 1980.

[9] E. S. Mooberry, H. W. Spiess, and R. K. Sheline, J. Chem. Phys. 57, 813 (1972).

[10] S. L. Segel and R. G. Barnes, Phys. Rev. 107, 638 (1969).

[11] S. L. Segel and L. A. Anderson, J. Chem. Phys. 49, 1407 (1968).

[12] H. Schmidbaur, D. Koth, and P. K. Burkert, Chem. Ber. 107, 269 (1974).

[13] P. K. Burkert, D. Koth, and H. Schmidbaur, Z. Naturforsch. 31 b, 149 (1976).

[14] P. K. Burkert and M. F. Eckel, Z. Naturforsch. 28b, 5 (1973).

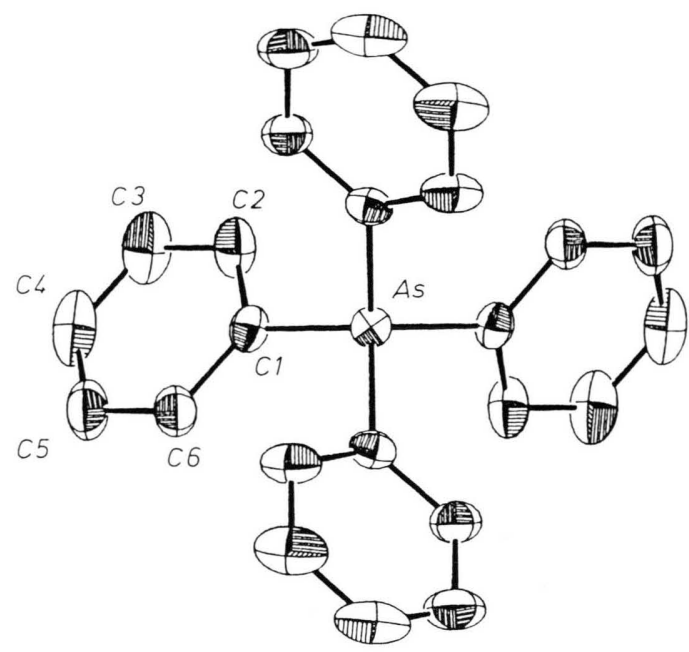

Fig. 4. Substituent geometry of the tetraphenylarsonium cation.

movements of the periodate anions themselves leading to the same effects as described by the reorientation model [18].

\section{Acknowledgement}

We wish to express our gratitude to Professor Dr. H. P. Fritz, Institute of Inorganic Chemistry, Technical University of Munich, for financial support of this research.

[15] P. K. Burkert and M. F. Eckel, Z. Naturforsch. 28b, 379 (1973).

[16] P. K. Burkert and F. M. Hutter, Z. Naturforsch. 32 b, 15 (1977).

[17] P. K. Burkert, Z. Naturforsch. 35 b, 1349 (1980).

[18] K. Negita, N. Nakamura, and H. Chihara, Chem. Phys. Lett. 63, 187 (1979).

[19] P. K. Burkert, J. Mol. Struct. 58, 307 (1982).

[20] W. Wolfsberger and H. Schmidbaur, Synth. React. Inorg. Met.-Org. Chem. 4, 149 (1974).

[21] G. F. Fenton, L. Hey, and C. K. Ingold, J. Chem. Soc. 1933, 989.

[22] M. E. P. Friedrich and C. S. Marvel, J. Amer. Chem. Soc. 52, 378 (1930).

[23] M. M. Baig and W. R. Cullen, Can. J. Chem. 39, 420 (1961).

[24] W. J. C. Dyke and W. J. Jones, J. Chem. Soc. 1930, 2426.

[25] G. H. Stauss, J. Chem. Phys. 40, 1988 (1964).

[26] J. F. Baugher, P. C. Taylor, T. Oja, and P. J. Bray, J. Chem. Phys. 50, 4914 (1969).

[27] S. L. Segel, R. J. C. Brown, and R. D. Heyding, J. Chem. Phys. 69, 3435 (1978).

[28] U. Müller, Acta Crys. B 36, 1075 (1980). 